\title{
Hot Deformation Behaviors of as Cast 321 Austenitic Stainless Steel
}

\author{
Deli Zhao ${ }^{1}$, Liguo Ren ${ }^{1}$, Yong Wang ${ }^{2}{ }^{\mathbb{D}}$, Wei Wang ${ }^{1}$, Zhe Zhu ${ }^{1}$ and Wantang Fu ${ }^{1, *}$ \\ 1 State Key Laboratory of Metastable Materials Science and Technology, Yanshan University, \\ Qinhuangdao 066004, China; zhaodel@gmail.com (D.Z.); renliguo407@163.com (L.R.); \\ wangweiysus@163.com (W.W.); zz.666@foxmail.com (Z.Z.) \\ 2 School of Mechanical Engineering, Yanshan University, Qinhuangdao 066004, China; \\ 528812958@stumail.ysu.edu.cn \\ * Correspondence: wtfu@ysu.edu.cn; Tel.: +86-33-5805-8701
}

Citation: Zhao, D.; Ren, L.; Wang, Y.; Wang, W.; Zhu, Z.; Fu, W. Hot Deformation Behaviors of as Cast 321 Austenitic Stainless Steel. Metals 2021, 11, 1245. https://doi.org/10.3390/ met11081245

Academic Editor: Tilmann Beck

Received: 2 July 2021

Accepted: 3 August 2021

Published: 5 August 2021

Publisher's Note: MDPI stays neutral with regard to jurisdictional claims in published maps and institutional affiliations.

Copyright: (c) 2021 by the authors. Licensee MDPI, Basel, Switzerland. This article is an open access article distributed under the terms and conditions of the Creative Commons Attribution (CC BY) license (https:/ / creativecommons.org/licenses/by/ $4.0 /)$.

\begin{abstract}
AISI 321 stainless steel has excellent resistance to intergranular corrosion and is generally used in nuclear power reactor vessels and other components. The as-cast and wrought structures are quite different in hot workability, so physical simulation, electron back-scatter diffraction, and hot processing maps were used to study the mechanical behavior and microstructure evolution of as-cast nuclear grade 321 stainless steel in the temperature range of $900-1200{ }^{\circ} \mathrm{C}$ and strain rate range of $0.01-10 \mathrm{~s}^{-1}$. The results showed that the flow curve presented work-hardening characteristics. The activation energy was calculated as $478 \mathrm{~kJ} / \mathrm{mol}$. The fraction of dynamic recrystallization (DRX) increased with increasing deformation temperature and decreasing strain rate. DRX grain size decreased with increasing $Z$ value. Combining the hot working map and DRX state map, the suggested hot working window was $1000-1200{ }^{\circ} \mathrm{C}$ and $0.01-0.1 \mathrm{~s}^{-1}$. The main form of instability was necklace DRX. The nucleation mechanism of DRX was the migration of subgrains. The $\delta$ phase reduced the activation energy and promoted DRX nucleation of the tested steel.
\end{abstract}

Keywords: 321 stainless steel; cast structure; hot deformation; dynamic recrystallization; flow instability

\section{Introduction}

AISI 321 stainless steel contains $0.44 \%$ Ti to stabilize C, which reduces intergranular precipitates such as M23C6. This steel therefore has excellent intergranular corrosion resistance [1,2]. In addition, it has outstanding oxidation resistance and high-temperature mechanical properties [3,4]. As a candidate structural material for the low-pressure system of the fourth-generation sodium-cooled fast neutron reactor, it is mainly used for components such as reactor vessels, primary loop sodium-sodium reaction heat exchangers, and primary and secondary loop main pipelines [3]. There are many reports concerning the hot stability and mechanical properties [4,5], resistance to intergranular corrosion [2], surface processing properties [6], and welding properties of 321 stainless steel [1].

AISI 321 stainless steel contains about $18 \% \mathrm{Cr}$ and $10 \% \mathrm{Ni}$. For this kind of steel, surface cracking usually occurs during hot forging [7]. Coarse and mixed grains cause difficulty in structure control [8,9]. Mehdi et al. [10] studied flow behavior of wrought 321 stainless steel and obtained an activation energy of $433 \mathrm{~kJ} / \mathrm{mol}$. Richard et al. [11] compared the flow behaviors of 321 and 304 stainless steels, finding that the steady-state stress of 321 was lower than that of 304 for the same $Z$ value. A constitutive model of the rolling load of 321 austenitic stainless steel was subsequently established [12]. Ghazani et al. found that the dynamic recovery (DRV) kinetics are more sensitive to deformation rate than deformation temperature [13]. In addition, electron back-scatter diffraction (EBSD) results of microstructure evolution showed that the main softening process in the temperature range of $800-950^{\circ} \mathrm{C}$ is DRV, and dynamic recrystallization DRX is the main softening mechanism at $1000-1200{ }^{\circ} \mathrm{C}$ [14]. Anoop et al. [15] established the hot deformation constitutive equation of wrought 321 stainless steel and a processing map was drawn. 
Reports on the hot workability of 321 stainless steel mainly focus on the wrought structure. The cast structure of 321 stainless steel often has a larger size of $\delta$ phase [16], as well as $\mathrm{TiN}, \mathrm{TiC}$, and other precipitates, which differ from the wrought structure in terms of size, morphology, and distribution. Owing to the large differences between the cast and wrought structures of steels, there are obvious differences in hot workability $[16,17]$.

The present work aimed to examine the mechanical behavior and microstructural changes during hot deformation, to clarify the deformation mechanism and, combined with the hot processing map, to provide a theoretical basis for structure control and the forging process of nuclear grade as-cast 321 stainless steel.

\section{Materials and Methods}

AISI 321 austenitic stainless steel was melted using a vacuum electroslag smelting and vacuum casting process, the gating system of the tested steel is shown in Figure 1, and the degree of vacuum was less than $67 \mathrm{~Pa}$. The diameter of the specimen was $1.98 \mathrm{~m}$ and the mass was $93 \mathrm{t}$. The chemical composition was as follows (mass\%): $0.05 \mathrm{C}, 17.98 \mathrm{Cr}$, 10.15 Ni, 2.0 Mn, 0.73 Si, 0.44 Ti, 0.34 Mo, and 0.05 Cu. Compression test specimens $(\Phi$ $10 \mathrm{~mm} \times 15 \mathrm{~mm}$ ) were machined along the lateral direction of the columnar crystal, and the position of the compressed tested samples is shown in Figure 2.
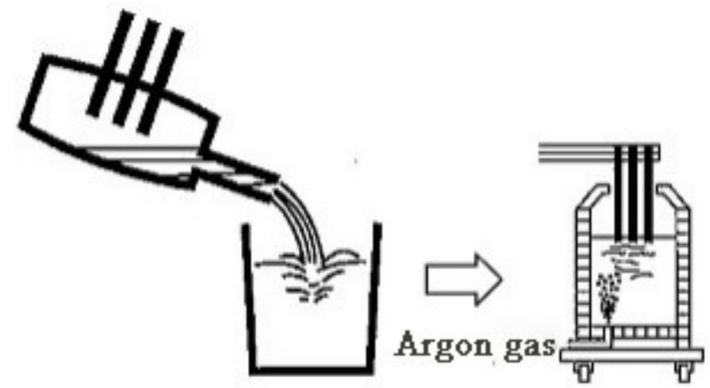

Alkalescent Arc Furnace Ladle Refining Furnace

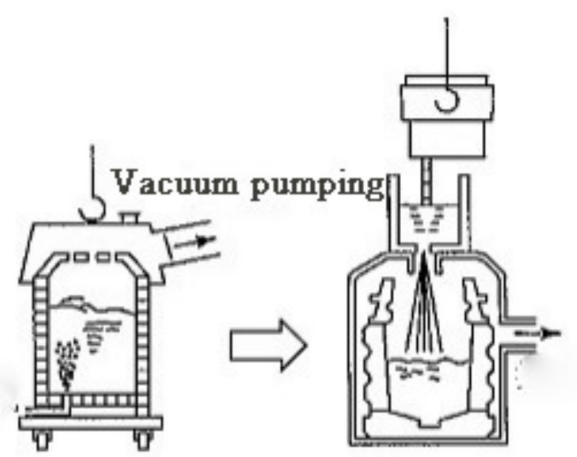

Vacuum Casting

Figure 1. The gating system of the tested steel.

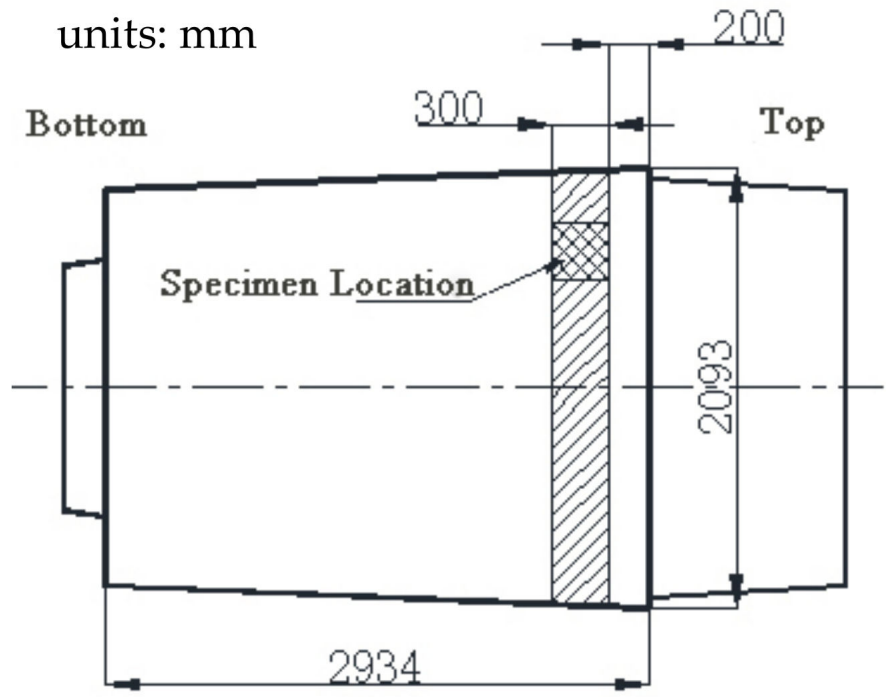

Figure 2. The position of the compressed tested samples. 
Hot compression tests were conducted on a Gleeble 3500 (Dynamic Systems Inc., New York, NY, USA) thermal/mechanical simulator. The samples were preheated to $1200{ }^{\circ} \mathrm{C}$ for $60 \mathrm{~s}$, cooled at $10{ }^{\circ} \mathrm{C} / \mathrm{s}$ to the deformation temperature $\left(900{ }^{\circ} \mathrm{C}, 1000{ }^{\circ} \mathrm{C}, 1100{ }^{\circ} \mathrm{C}\right.$, and $1200^{\circ} \mathrm{C}$ ), then compressed to a strain of 0.8 at strain rates of $0.01,0.1,1$, and $10 \mathrm{~s}^{-1}$ and quenched immediately. The samples were ground and polished with $2000 \mathrm{Cw}$ sandpaper and then diamond paste with a size no larger than $2.5 \mu \mathrm{m}$. The polished surface was etched with $50 \%$ aqua regia solution for $15 \mathrm{~s}$ and the microstructures observed by optical microscope. The ground specimens were electro-polished with a solution of 1:19 $\mathrm{HClO}_{4}$ $\mathrm{CH}_{3} \mathrm{CH}_{2} \mathrm{OH}$ at $0.4 \mathrm{~mA}$ for $1 \mathrm{~min}$ prior to EBSD (EDAX Inc., Mahwah, USA) analysis using TSL OIM analysis software (Version 8, EDAX Inc., Mahwah, NJ, USA).

A phase map of the original sample is shown in Figure 3, in which austenite is colored in red and $\delta$ is colored in green. The fraction of $\delta$ was $0.5 \%$.

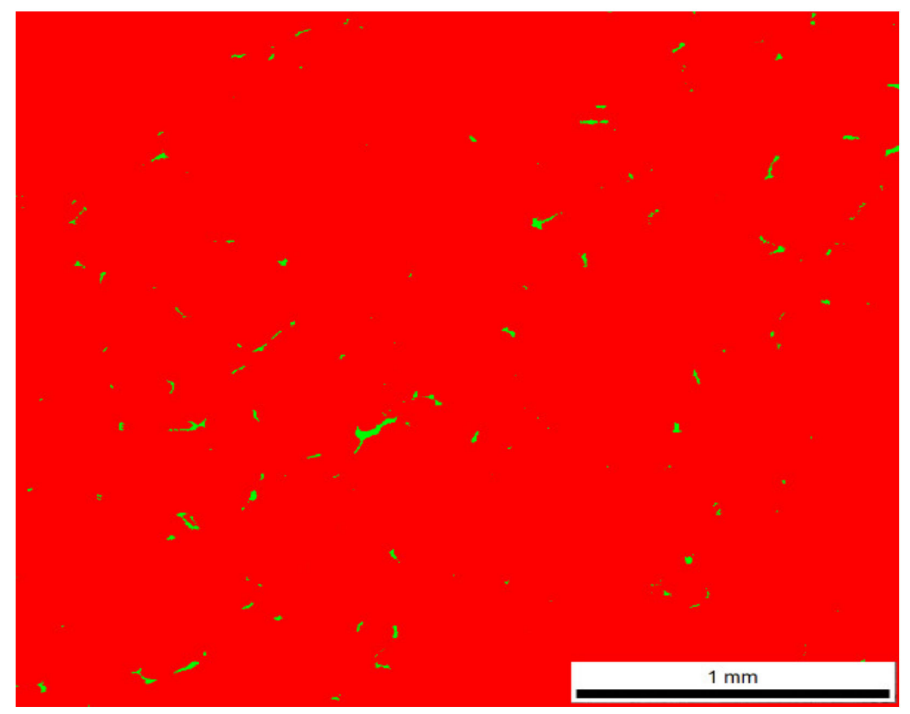

Figure 3. Phase map of original sample.

\section{Results}

\subsection{Flow Behavior and Hot Deformation Equation}

The flow curves of the tested steel compressed under different conditions are shown in Figure 4. The flow stress increased with the decrease of temperature and increase of strain rate. In the initial stage of plastic deformation, the stress increased rapidly with the increase of strain and work hardening was dominant. With the increase of strain, the stress slowly increased and the work-hardening rate gradually decreased, but the dynamic softening effect was not sufficient to offset the hardening effect of hot working. Under the same strain rate, it was found that the higher the temperature, the lower was the work hardening rate and the greater the degree of softening.

It is interesting to note that there was no obvious peak stress during the hot compression process. Poliak et al. [18] indicated that although DRX had occurred, there was no obvious peak stress on the flow curves. However, flow curves often show obvious softening for single-phase austenitic stainless steel $[10,14,15]$. This may be related to the existence of the $\delta$ phase because flow curves do not only reflect the work-hardening and dynamic softening behavior of single-phase austenite. In addition, different deformation mechanisms may affect the flow curves, such as cracking and flow instabilities [10]. Therefore, it is not accurate to predict the deformation mechanism by solely relying on the flow curves. 

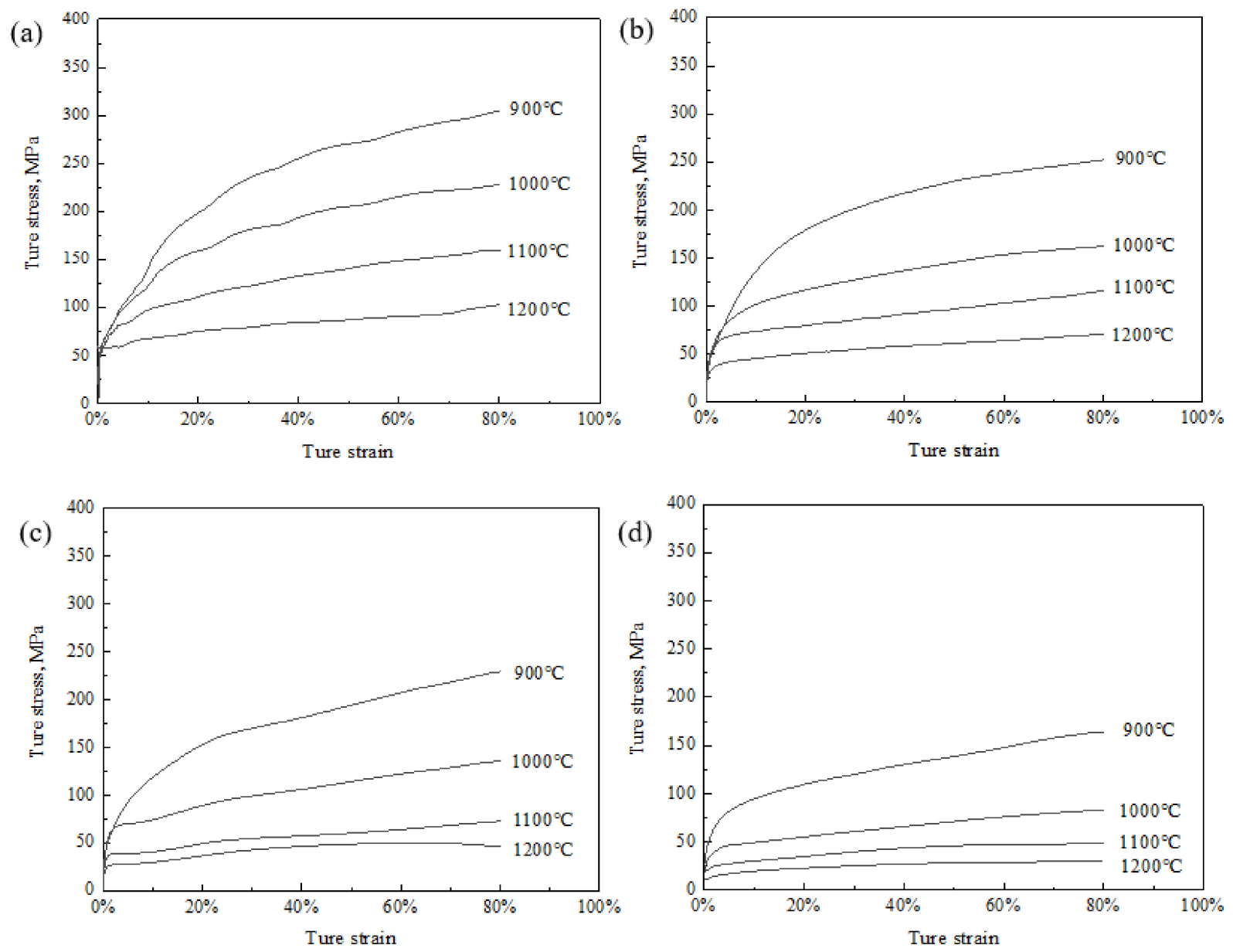

Figure 4. Flow curves of tested steel under different stain rate conditions: (a) $10 \mathrm{~s}^{-1}$; (b) $1 \mathrm{~s}^{-1}$; (c) $0.1 \mathrm{~s}^{-1}$; (d) $0.01 \mathrm{~s}^{-1}$.

Deformation temperature and strain rate have significant influence on the hot deformation process. The relationship between flow stress, strain rate, and deformation temperature of a metal during hot deformation can be described by the classic hyperbolic sine formula [19]. Since there was no obvious peak stress in the flow curves, the stress values at a strain of $80 \%$ were selected in this study. According to literature [20], the relationships between $\ln \sigma-\ln \dot{\varepsilon}$ and $\sigma-\ln \dot{\varepsilon}$ can be obtained by simplifying the hyperbolic sine function, as shown in Figure 5a,b, respectively. These results show that $\ln \sigma-\ln \dot{\varepsilon}$ and $\sigma-\ln \dot{\varepsilon}$ are approximately linear. Parameter $\alpha$ was determined as 0.00948 by linear regression.

Taking the natural logarithm of both sides of the hyperbolic sine function according to the flow curve data of Figure 4, the relationship curves of $\ln [\sinh (\alpha \sigma)]$ vs. $\ln \dot{\varepsilon}$ and $\ln [\sinh (\alpha \sigma)]$ vs.1/T were obtained as shown in Figure $5 c, d$, respectively. The value of each parameter was obtained by linear regression: $\mathrm{A}$ is $5.81 \times 1019, \mathrm{n}$ is 5.05 , and $\mathrm{Q}$ is $478 \mathrm{~kJ} / \mathrm{mol}$.

Therefore, the hot deformation equation of the tested steel under the deformation conditions of $900-1200{ }^{\circ} \mathrm{C}$ and $0.01-10 \mathrm{~s}^{-1}$ is:

$$
\dot{\varepsilon}=5.81 \times 10^{19}[\sinh (0.00948 \sigma)]^{5.05} \exp (-478,000 / \mathrm{RT})
$$



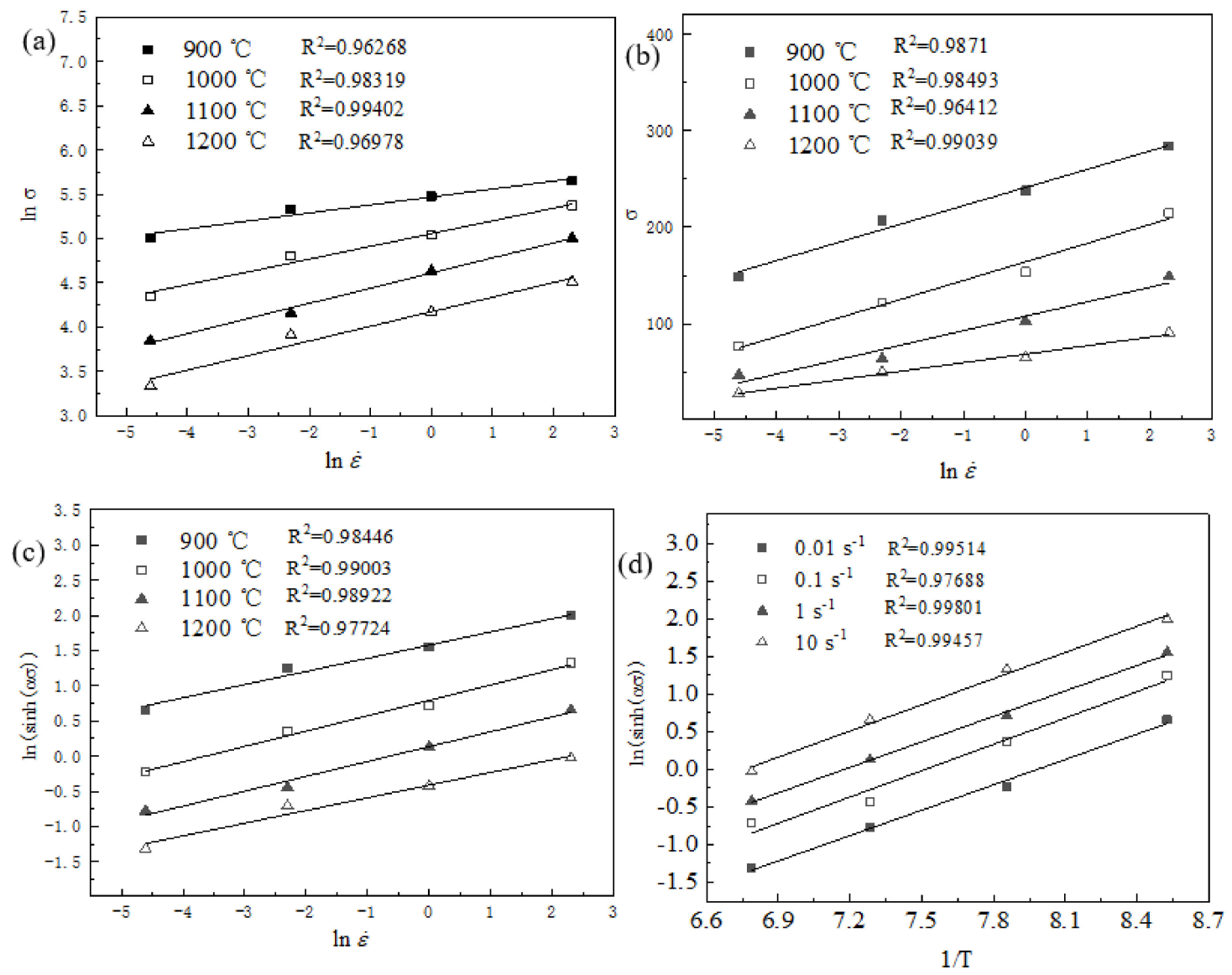

Figure 5. The relationship of various parameters: (a) $\ln \sigma-\ln \dot{\varepsilon} ;(\mathbf{b}) \sigma-\ln \dot{\varepsilon} ;(\mathbf{c}) \ln [\sinh (\alpha \sigma)]-\ln \dot{\varepsilon} ;(\mathbf{d}) \ln [\sinh (\alpha \sigma)]-1 / \mathrm{T}$.

\subsection{Microstructure Observation}

Figure 6 shows the microstructure after deformation at a strain rate of $1 \mathrm{~s}^{-1}$ at different temperatures. The gray islands are $\delta$ ferrite. When DRX occurs, fine and equiaxed grains replace the coarse deformed grains [21]. Based on the size and morphology of grains, the occurrence of DRX can be identified. Figure $6 \mathrm{a}\left(900^{\circ} \mathrm{C}\right)$ shows deformed parent grains and large-size deformed $\delta$. Figure $6 \mathrm{~b}\left(1000{ }^{\circ} \mathrm{C}\right)$ shows some fine DRX grains produced at the grain boundary, presenting as typical necklace DRX [22]. In Figure $6 \mathrm{c}\left(1100^{\circ} \mathrm{C}\right)$, many sub-crystal grains are found in the parent grain, the density of which is higher at the phase and grain boundaries. DRX grains nucleated at the phase boundary grew to a size of about $35 \mu \mathrm{m}$. In Figure $4 \mathrm{~d}\left(1200^{\circ} \mathrm{C}\right)$, the deformed parent crystal had completely disappeared: complete DRX had occurred and the grain size was about $52 \mu \mathrm{m}$. Therefore, under the same strain rate, the higher the temperature, the higher was the fraction of DRX and the larger was the DRX grain size. 

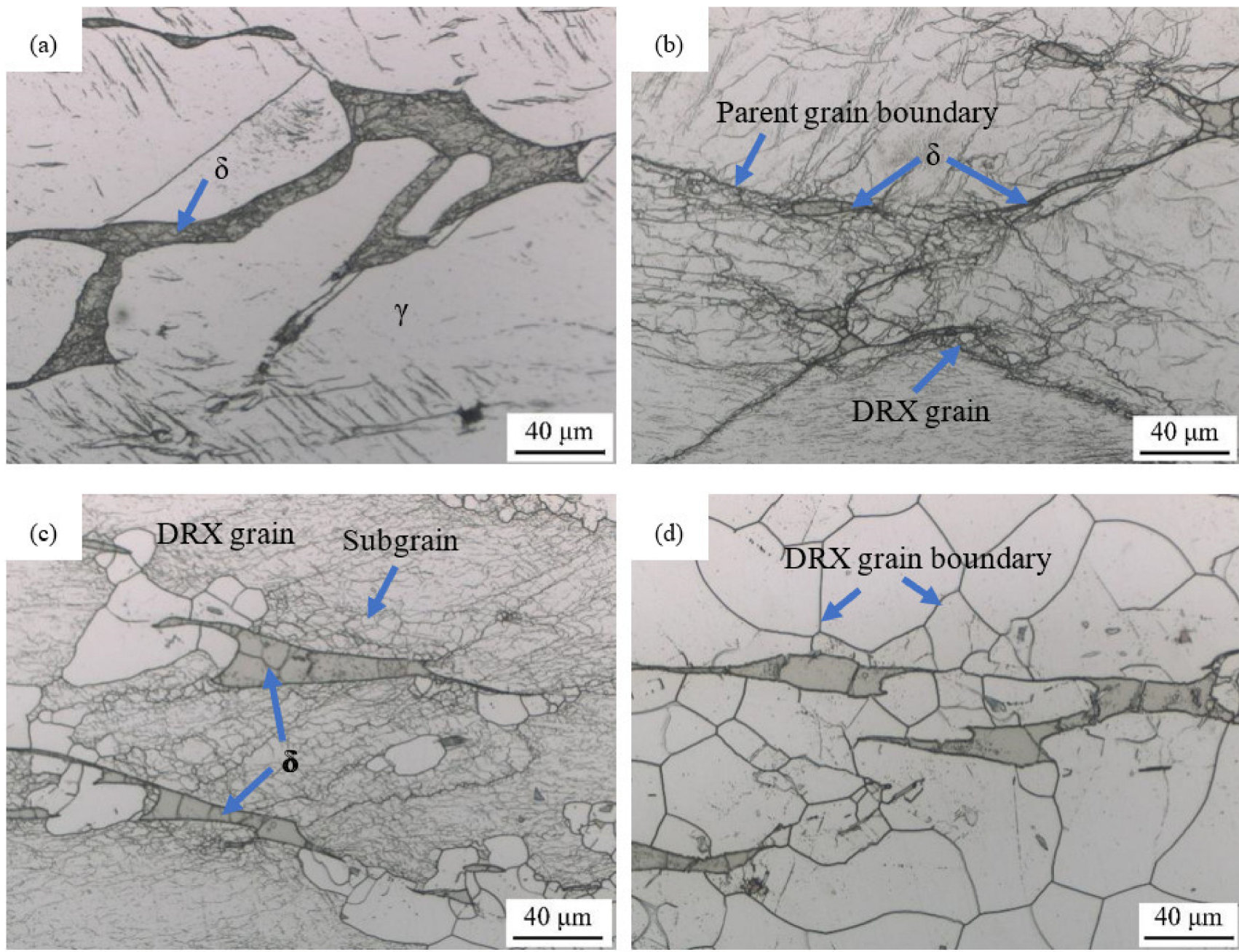

Figure 6. The microstructure of the tested steel at a strain rate of $1 \mathrm{~s}^{-1}$ at different temperatures: (a) $900{ }^{\circ} \mathrm{C}$; (b) $1000{ }^{\circ} \mathrm{C}$; (c) $1100{ }^{\circ} \mathrm{C} ;(\mathbf{d}) 1200{ }^{\circ} \mathrm{C}$.

The deformed microstructure of the tested steel at $1200{ }^{\circ} \mathrm{C}$ and different strain rates is shown in Figure 7. The grain size in Figure $7 \mathrm{a}$ is $73 \mu \mathrm{m}$, while that in Figure $7 \mathrm{~b}$ is $29 \mu \mathrm{m}$. The DRX grain size gradually decreased with the increase of the strain rate.
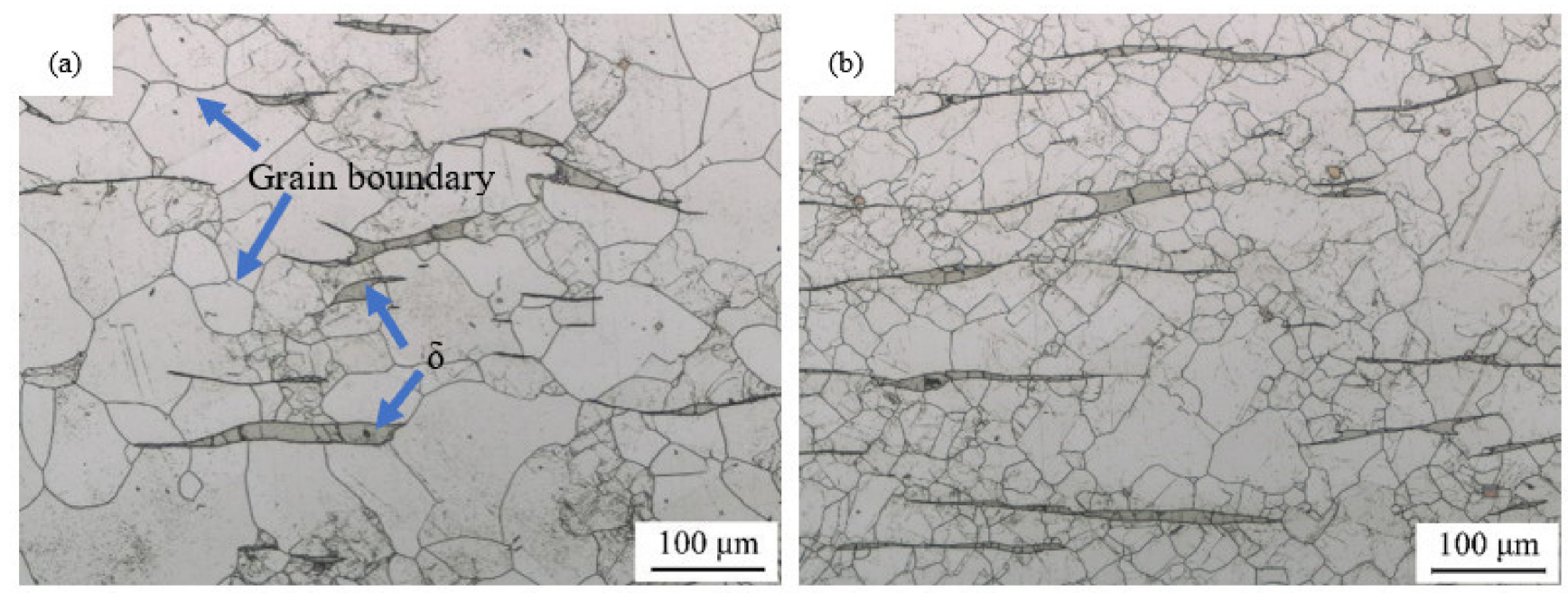

Figure 7. The microstructure at $1200^{\circ} \mathrm{C}$ with different strain rates: (a) $0.1 \mathrm{~s}^{-1}$; (b) $10 \mathrm{~s}^{-1}$. 
At the same temperature, the higher the strain rate, the faster is the accumulation of dislocations, which provide more nucleation sites for DRX, especially when the hardness of $\delta$ and $\gamma$ differ at high temperature and the deformation is inconsistent [23], which promotes the accumulation of dislocations. DRX grains then have enough time to grow at low strain rate. Therefore, the higher the strain rate, the smaller is the DRX grain size. In addition, Wang et al. [24] found that a too low a strain rate is conducive to dislocation climbing and the formation of dislocation walls and entanglements. In this case, DRX is inhibited.

According to literature [25], the fraction of DRX grains in the tested steel under different conditions was measured by the binary method and the statistical results are shown in Figure 8. The microstructure of specimens deformed at $900-1200{ }^{\circ} \mathrm{C}$ and $0.01-10 \mathrm{~s}^{-1}$ (total 16 deformation conditions) were observed. In the microstructure maps, the DRX grains were covered by black and the deformed parent grains were white. The fraction of DRX was measured through quantitative metallography. The statics results are shown in Figure 8. The contour line represents the fraction of DRX, light gray corresponds to the area of complete DRX, and dark gray corresponds to the area without DRX. The DRX fraction increased with the increase of deformation temperature and decrease of strain rate.

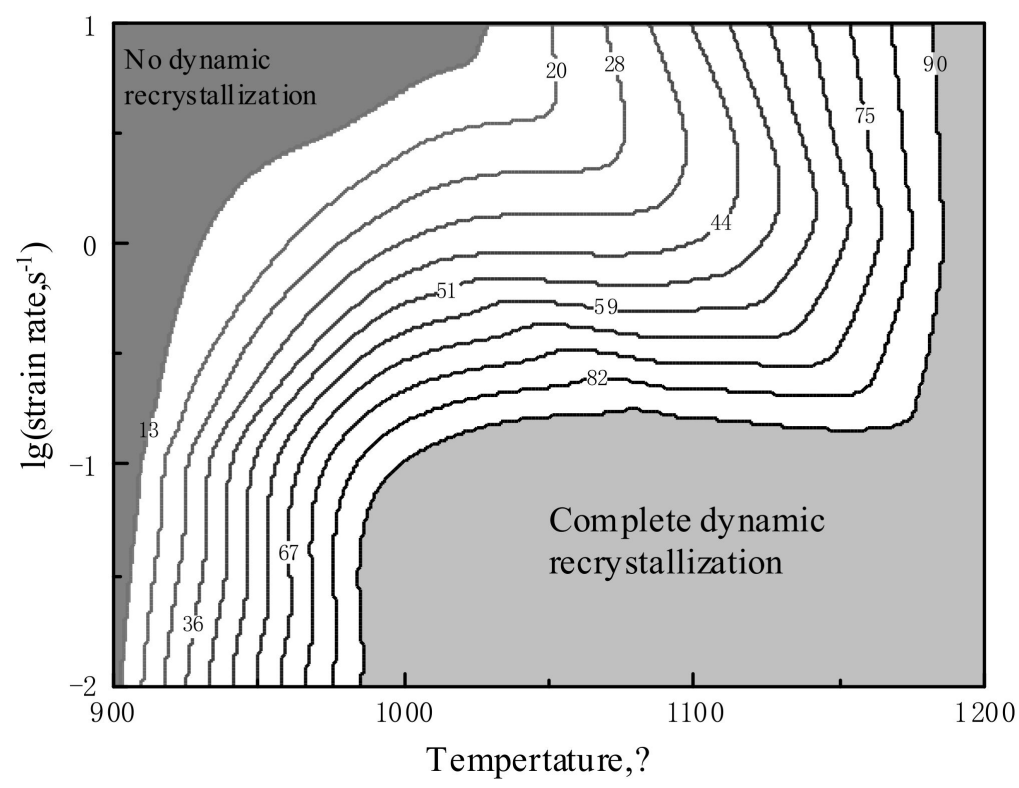

Figure 8. DRX state map of tested steel.

The DRX grain size under different conditions was measured by the section method. It is related to the parameters $\mathrm{Z}$ and A [26], where A and Equation (1) are the same parameter. The Zener-Hollomon parameter is widely used to characterize the combined effect of temperature and strain rate on deformation. The $\mathrm{Z}$ parameters of the tested steel are as follows:

$$
\mathrm{Z}=\dot{\varepsilon} \exp (478,000 / \mathrm{RT})
$$

Therefore, the relationship between $\ln (\mathrm{D})$ and $\ln (\mathrm{Z} / \mathrm{A})$ can be obtained, as shown in Figure 9.

Corresponding to the points in Figure 9 after linear fitting, the $R^{2}$ is 0.75859 , and the relationship between the recrystallized grain size $\mathrm{D}$ and the parameters $\mathrm{Z}$ and $\mathrm{A}$ is:

$$
\mathrm{D}=1.301 \times(\mathrm{Z} / \mathrm{A})^{-0.355}(\mu \mathrm{m})
$$




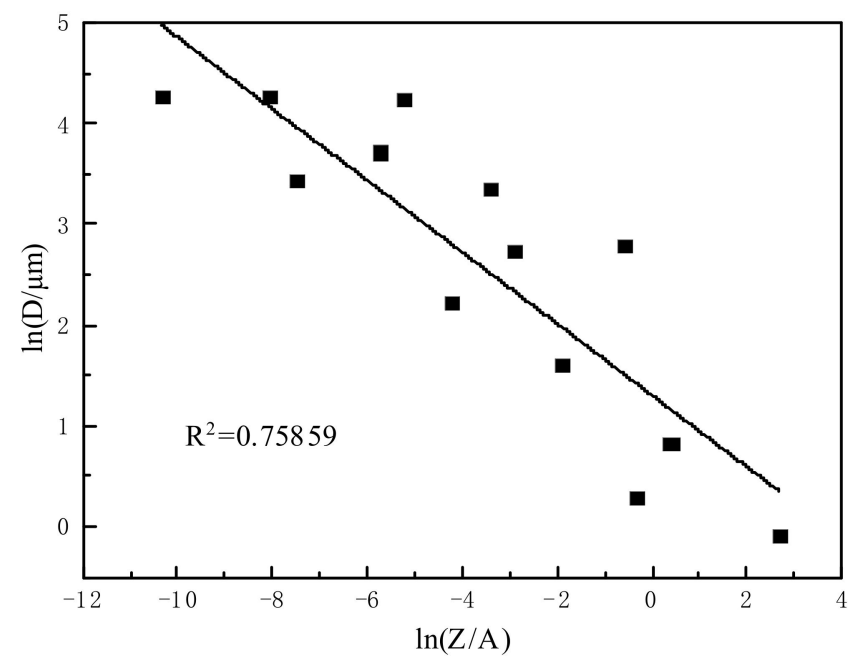

Figure 9. The relationship between the DRX grain size D and the parameters $\mathrm{Z}$ and $\mathrm{A}$.

\subsection{Hot Processing Maps}

According to the hot working map theory based on the dynamic material model proposed by Prasad et al. [25], the power dissipation ratio and plastic flow instability criteria are expressed by Equations (4) and (5), respectively:

$$
\begin{gathered}
\eta=\frac{J}{J_{\max }}=\frac{2 \mathrm{~m}}{\mathrm{~m}+1} \\
\xi=\left\{\frac{\partial \ln \left[\frac{\mathrm{m}}{\mathrm{m}+1}\right]}{\partial \ln \dot{\varepsilon}}\right\}+\mathrm{m}<0
\end{gathered}
$$

where $\mathrm{J}$ is the power consumed due to changes in the microstructure, $\mathrm{J}_{\max }$ is the total power consumed by the entire system, and $\mathrm{m}$ is the strain rate sensitivity index.

The hot processing map was obtained from $\eta$ and $\xi$, as shown in Figure 10. The shaded region corresponds to the flow instability and the contour numbers represent the percent efficiency of dissipation.

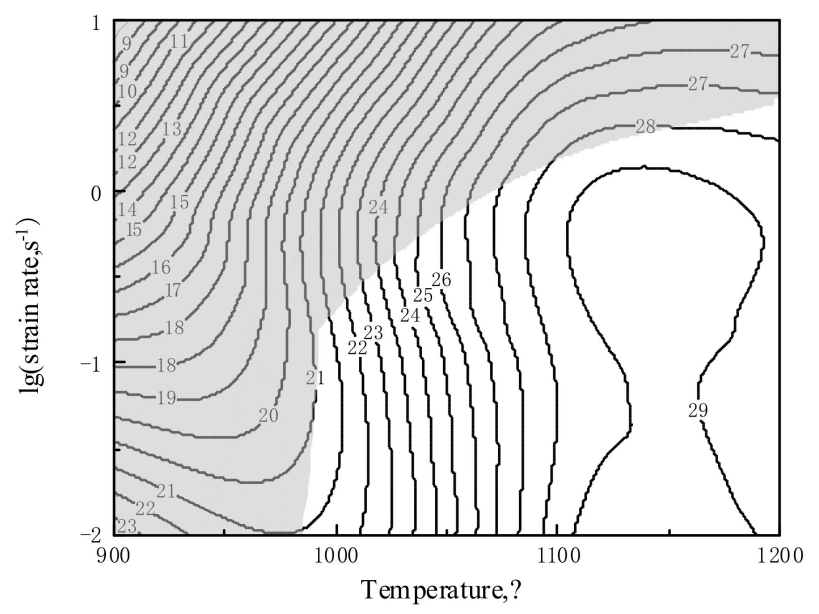

Figure 10. Processing map of tested steel at a strain of 0.8 .

The characteristics of power dissipation at a strain of 0.8 are as follows: Power dissipation increased with the increase of temperature and decrease of strain rate. When the temperature exceeded $1100^{\circ} \mathrm{C}$, the sensitivity of power dissipation to the change of strain rate decreased: The maximum value was about $29 \%$. The flow instability mainly corresponded to low power dissipation. Combined with the DRX state map (Figure 8), it 
was found that the zones of flow instability and incomplete DRX have a higher degree of overlap.

Ghazani et al. [27] indicated that the critical damage value increases with the increase of deformation temperature and decrease of strain rate, and the lower the critical damage value, the higher is the risk of plastic fracture. The processing windows with the lowest fracture risk for 321 stainless steel are $0.001 \mathrm{~s}^{-1}, 1025-1075{ }^{\circ} \mathrm{C}$, and $1150-1200{ }^{\circ} \mathrm{C}$. The distribution flow instability zone in literature [15] is similar to that reported in this paper, but the safe processing temperature is lower at $900-1000{ }^{\circ} \mathrm{C}$. The coarse-grained structure may be the reason because this is more dependent on high temperature than the finegrained structure. Therefore, the safe processing window of the tested steel is $1000-1200{ }^{\circ} \mathrm{C}$ and $0.01-0.1 \mathrm{~s}^{-1}$.

\subsection{Instability Mechanism}

The microstructure of the flow instability zone at a strain of 0.8 is shown in Figure 11. The necklace structure was found under two conditions: fine DRX grains were distributed on the parent grain boundary and phase boundary, which is a typical characteristic of flow instability [22]. Jafari et al. [28] indicated that when materials with coarse-grained structure are deformed at a higher strain rate, shear deformation often occurs at the grain boundaries, which form a smaller range of shear bands. As a result, the deformation is uneven between the grain boundary and within the grain. As dislocations multiply at the grain boundary, the shape of the grain boundary fluctuates more and more, and the sawtooth and bow shapes become increasingly obvious as the strain reaches the peak critical strain, as shown by the red line in Figure 11c. Necklace DRX grains are finally formed along parent grain boundaries.
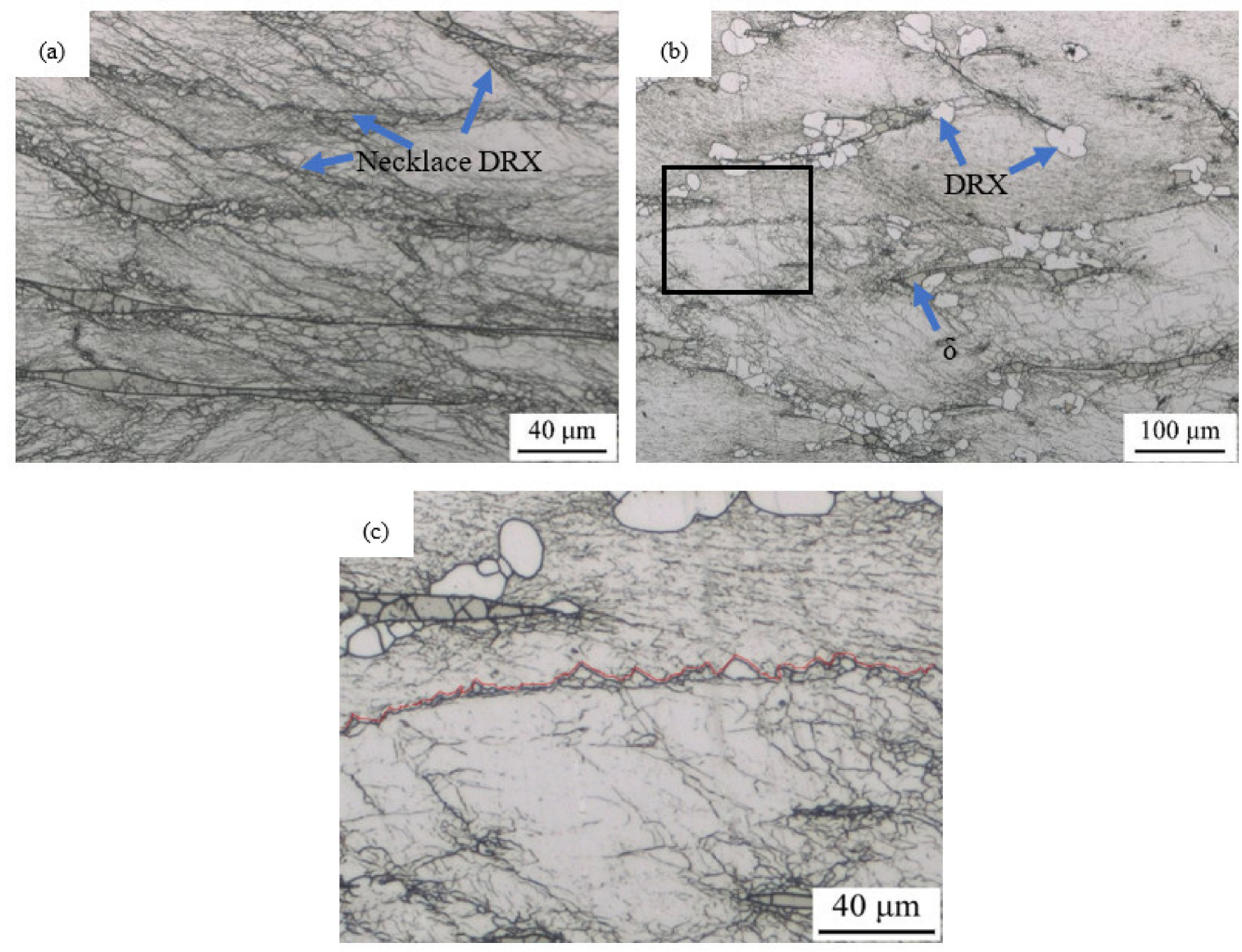

Figure 11. The microstructure of flow instability: (a) $1000^{\circ} \mathrm{C}, 1 \mathrm{~s}^{-1}$; (b) $1100{ }^{\circ} \mathrm{C}, 1 \mathrm{~s}^{-1}$; (c) Enlargement of the black box area in $(\mathbf{b})$. 


\section{Discussion}

Figures 12 and 13 show the inverse pole figure (IPF) and kernel average misorientation (KAM) maps of the specimen deformed at $1000^{\circ} \mathrm{C}, 0.01 \mathrm{~s}^{-1}$, and $1100^{\circ} \mathrm{C}, 1 \mathrm{~s}^{-1}$, respectively. Figures $12 \mathrm{c}$ and $13 \mathrm{c}$ show the IPF maps with grain boundaries. The high-angle grain boundaries (HAGB; misorientations $\geq 15^{\circ}$ ) are shown as black lines, twin boundaries are shown as red lines, and low-angle grain boundaries (LAGB; $2^{\circ} \leq$ misorientations $<15^{\circ}$ ) are shown as gray lines.

There are LAGBs at the boundary between regions with no DRX and $\delta$, as shown in the black ellipses in Figures 12c and 13c. This indicates that DRX arose from the migration of subgrains, due to the slip and climb of dislocations forming substructures at the phase boundary. The density of subgrain boundary dislocations is relatively high during the process, so they gradually migrate into HAGBs at higher temperatures. The DRX mechanism of as-cast nuclear grade 321 stainless steel is the migration of subgrains.

Comparing Figure 12c,d, the KAM value of the DRX regions was smaller than that of regions without DRX. The smaller the KAM value, the lower is the dislocation density. The occurrence of DRX contributes to the elimination of defects such as dislocations.

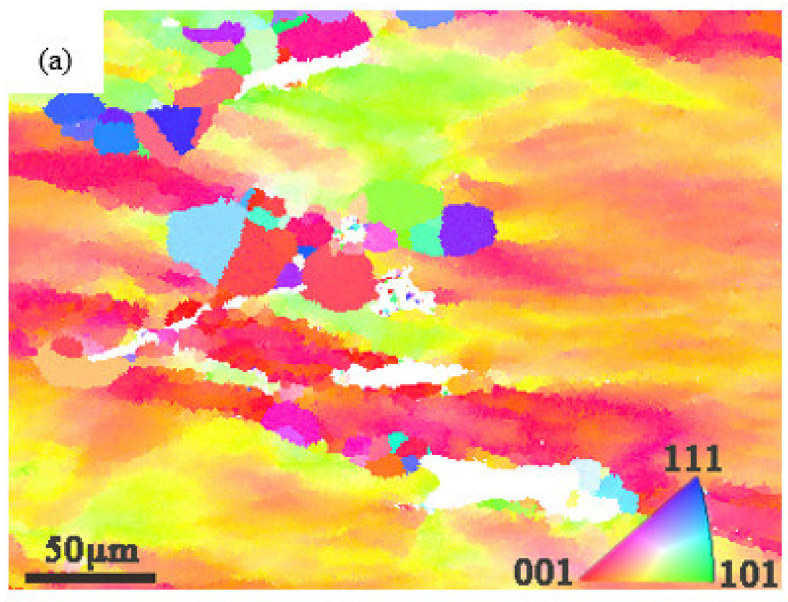

(b)
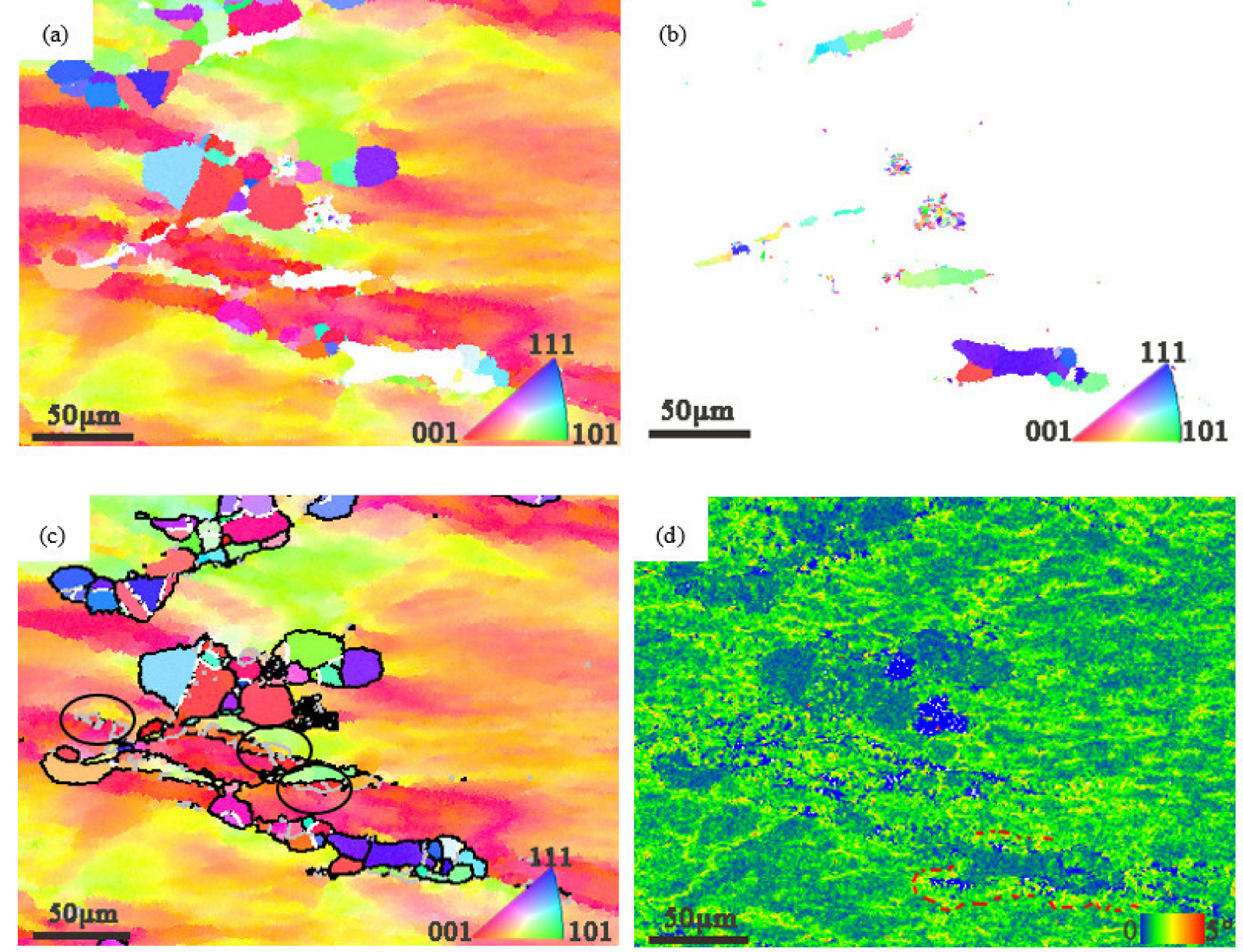

Figure 12. IPF map and KAM map under $1000{ }^{\circ} \mathrm{C}, 0.01 \mathrm{~s}^{-1}$ conditions: (a) IPF map of austenitic steel; (b) IPF map of $\delta$; (c) IPF map and grain boundary; (d) Corresponding KAM map. 

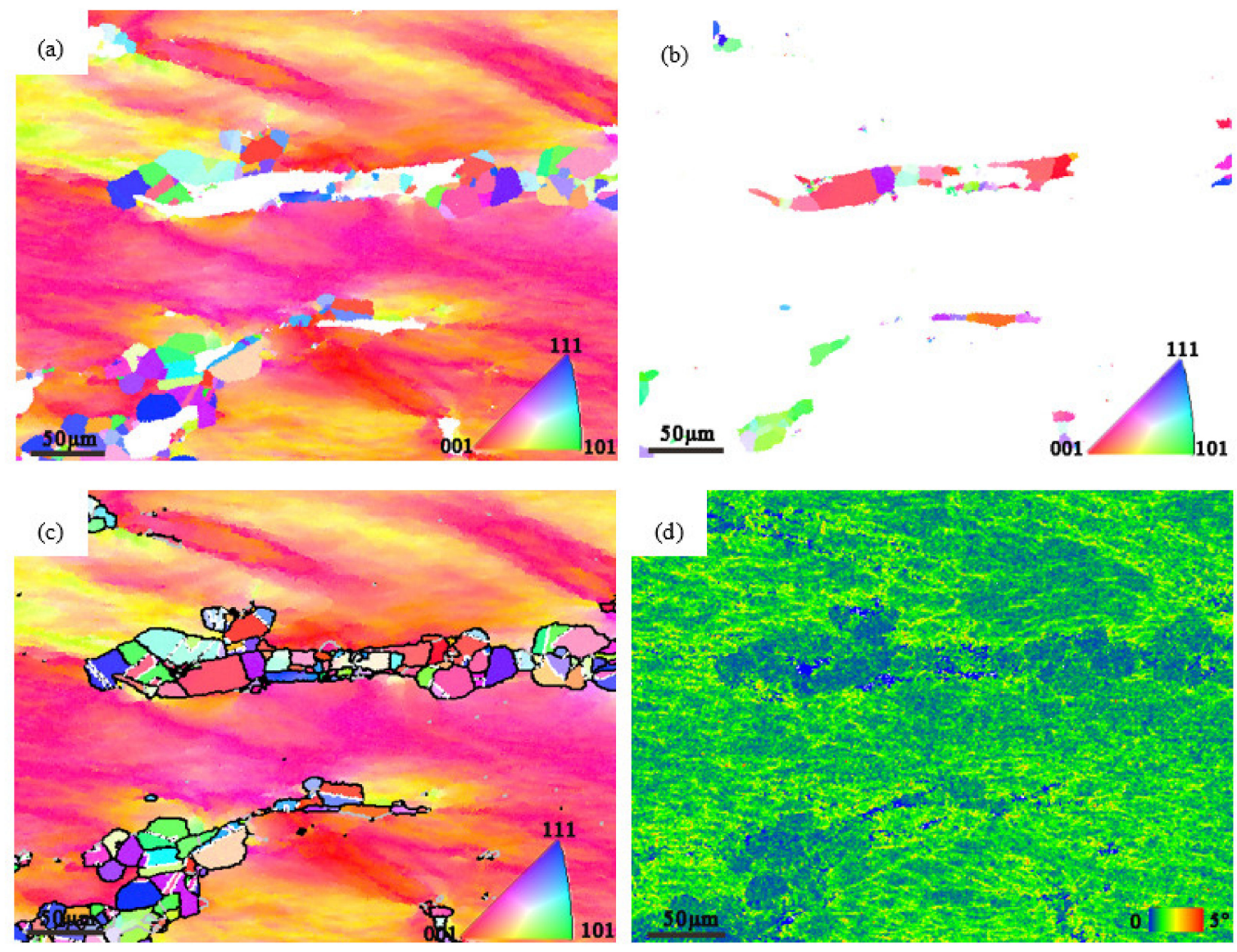

Figure 13. IPF map and KAM map under $1100{ }^{\circ} \mathrm{C}, 1 \mathrm{~s}^{-1}$ conditions: (a) IPF map of austenitic; (b) IPF map of $\delta$; (c) IPF map and grain boundary; (d) Corresponding KAM map.

In Figures 12a and 13a, fine and strain-free grains were found around the $\delta$ ferrite. In addition, it can be seen from Figures $12 \mathrm{c}$ and $13 \mathrm{c}$ that there are some HAGBs between these fine grains. Therefore, it can be inferred that these are DRX grains. The orientation in each DRX grain is very uniform. In addition, the KAM values of DRX grains are relative lower than surrounding deformed matrix. Dislocations did not easily accumulate and plug at grain boundaries because of the scarcity of grain boundaries in the as-cast structure. However, there were a lot of phase boundaries in the tested steel, so when dislocations slipped to the phase boundary, they were plugged and caused the rise of KAM value, as shown in the red dotted region in Figure 12d. A cellular substructure was formed by multiplication of dislocations and subgrains, which finally transformed into DRX grains. $\delta$ promotes DRX of as-cast nuclear grade 321 austenitic stainless steel.

Previous studies have shown that the activation energy of as-cast structure steels is much higher than that of the wrought structure $[29,30]$. The activation energy of the tested steel was $478 \mathrm{~kJ} / \mathrm{mol}$, which is close to values reported for wrought steels of $465 \mathrm{~kJ} / \mathrm{mol}$ [11] and $445 \mathrm{~kJ} / \mathrm{mol}$ [27]. Therefore, promotion of $\delta$ in dynamic softening of coarse structures reduces the activation energy. In addition, alloying elements (besides carbon) can increase the activation energy [31]. Element segregation caused by $\delta$ may contribute to the activation energy of the coarse austenite structure. The $\delta$ phase reduces the activation energy and promotes the occurrence of DRX of nuclear grade 321 austenitic stainless steel. 


\section{Conclusions}

(1) The hot deformation equation of as-cast nuclear grade 321 austenitic stainless steel at $900-1200{ }^{\circ} \mathrm{C}$ and $0.01-10 \mathrm{~s}^{-1}$ is:

$$
\dot{\varepsilon}=5.81 \times 10^{19}[\sinh (0.00948 \sigma)]^{5.05} \exp (-478,000 / \mathrm{RT})
$$

(2) The fraction of DRX increased with the increase of deformation temperature and decrease of strain rate. The relationship between DRX grain size and $\mathrm{Z}$ and $\mathrm{A}$ is $(\mu \mathrm{m})$.

$$
\mathrm{D}=1.301 \times(\mathrm{Z} / \mathrm{A})^{-0.355}(\mu \mathrm{m})
$$

(3) Combining the hot working map and DRX state map, the suggested processing window is $1000-1200{ }^{\circ} \mathrm{C}$ and $0.01-0.1 \mathrm{~s}^{-1}$.

(4) Flow instability occurs under conditions of low temperature and high strain rate. The main form of instability is necklace DRX.

(5) The DRX mechanism of the tested steel is the migration of subgrains. The $\delta$ phase reduces the activation energy and promotes the occurrence of DRX.

Author Contributions: Conceptualization, methodology, formal analysis. D.Z.; investigation, D.Z., L.R. and Y.W.; resources, L.R., Y.W. and W.W.; data curation, Y.W., W.W. and Z.Z.; writing-original draft preparation, D.Z.; writing-review and editing, D.Z., L.R. and W.F.; visualization, Z.Z. and W.F.; supervision, D.Z., L.R., Y.W., W.W., Z.Z. and W.F.; project administration, W.F.; funding acquisition, W.F. All authors have read and agreed to the published version of the manuscript.

Funding: This research was funded by the S\&T Program of Hebei Province (No. 20311003D).

Institutional Review Board Statement: Not applicable.

Informed Consent Statement: Not applicable.

Data Availability Statement: Data sharing is not applicable.

Acknowledgments: We would like to express our gratitude to Shuhua Sun (School of Science, Yanshan University, China) for her support and help.

Conflicts of Interest: The authors declare no conflict of interest.

\section{References}

1. Johnson, P.; Murugan, N. Friction Stir Welding Of 321Stainless Steel Plates by Tungsten Lanthanum Tool and Its Joint Analyses. Mater. Today Proc. 2018, 5, 4235-4241. [CrossRef]

2. Wang, J.; Su, H.; Chen, K.; Du, D.; Zhang, L.; Shen, Z. Effect of $\delta$-ferrite on the stress corrosion cracking behavior of 321 stainless steel. Corros. Sci. 2019, 158, 108079. [CrossRef]

3. Tiamiyu, A.A.; Eskandari, M.; Sanayei, M.; Odeshi, A.G.; Szpunar, J.A. Mechanical behavior and high-resolution EBSD investigation of the microstructural evolution in AISI 321 stainless steel under dynamic loading condition. Mater. Sci. Eng. A 2016, 673, 400-416. [CrossRef]

4. Tiamiyu, A.; Odeshi, A.; Szpunar, J. Multiple strengthening sources and adiabatic shear banding during high strain-rate deformation of AISI 321 austenitic stainless steel: Effects of grain size and strain rate. Mater. Sci. Eng. A 2018, 711, 233-249. [CrossRef]

5. Tiamiyu, A.; Zhao, S.; Li, Z.; Odeshi, A.; Szpunar, J. Thermal and Mechanical Stability of Austenite in Metastable Austenitic Stainless Steel. Metall. Mater. Trans. A 2019, 50, 4513-4530. [CrossRef]

6. Li, W.; Chen, H.; Li, C.; Huang, W.; Chen, J.; Zuo, L.; Ren, Y.; He, J.; Zhang, S. Microstructure and tensile properties of AISI 321 stainless steel with aluminizing and annealing treatment. Mater. Des. 2021, 205, 109729. [CrossRef]

7. Kim, Y.; Nam, H.; Lee, J.; Park, C.; Moon, B.; Nam, D.-G.; Lee, S.H.; Kang, N. Hot-cracking resistivity of dissimilar clads using Inconel 52 and 308L stainless steel on carbon steel. J. Nucl. Mater. 2020, 533, 152103. [CrossRef]

8. Ye, L.; Zhai, Y.; Zhou, L.; Wang, H.; Jiang, P. The hot deformation behavior and 3D processing maps of $25 \mathrm{Cr} 2 \mathrm{Ni} 4 \mathrm{MoV}$ steel for a super-large nuclear-power rotor. J. Manuf. Process. 2020, 59, 535-544. [CrossRef]

9. Wang, L.; Li, Z.; Hu, X.; Lv, B.; Chen, C.; Zhang, F. Hot deformation behavior and 3D processing map of super austenitic stainless steel containing $7 \mathrm{Mo}-0.46 \mathrm{~N}-0.02 \mathrm{Ce}$ : Effect of the solidification direction orientation of columnar crystal to loading direction. $J$. Mater. Res. Technol. 2021, 13, 618-634. [CrossRef] 
10. Haj, M.; Mansouri, H.; Vafaei, R.; Ebrahimi, G.R.; Kanani, A. Hot compression deformation behavior of AISI 321 austenitic stainless steel. Int. J. Miner. Metall. Mater. 2013, 20, 529-534. [CrossRef]

11. Nkhoma, R.K.; Siyasiya, C.W.; Stumpf, W.E. Hot workability of AISI 321 and AISI 304 austenitic stainless steels. J. Alloy. Compd. 2014, 595, 103-112. [CrossRef]

12. Nkhoma, R.K.; Siyasiya, C.W.; Stumpf, W.E. Constitutive modelling of mill loads during hot rolling of AISI 321 austenitic stainless steel. Int. J. Mater. Res. 2014, 105, 907-921. [CrossRef]

13. Ghazani, M.S.; Eghbali, B.; Ebrahimi, G.R. Evaluation of the kinetics of dynamic recovery in AISI 321 austenitic stainless steel using hot flow curves. Trans. Indian Inst. Met. 2017, 70, 1755-1761. [CrossRef]

14. Ghazani, M.S.; Eghbali, B.; Ebrahimi, G. Kinetics and critical conditions for initiation of dynamic recrystallization during hot compression deformation of AISI 321 austenitic stainless steel. Met. Mater. Int. 2017, 23, 964-973. [CrossRef]

15. Anoop, C.; Singh, R.; Kumar, R.R.; Miyala, J.; Murty, S.N.; Tharian, K.T. Development and Validation of Processing Maps for Hot Deformation of Modified AISI 321 Austenitic Stainless Steel. Mater. Perform. Charact. 2020, 9, 150-169. [CrossRef]

16. Green, G.; Higginson, R.; Hogg, S.; Spindler, S.; Hamm, C.; Najorka, J. Analysis of ferrite formed in 321 grade austenitic stainless steel. Mater. Sci. Technol. 2015, 31, 418-425. [CrossRef]

17. Chen, H.; Wang, Z.; Qin, F.; Jia, P.; Zhao, X. Hot deformation behavior and processing maps of as-cast Mn18Cr18N steel. J. Wuhan Univ. Technol. Mater. Sci. Ed. 2017, 32, 935-943. [CrossRef]

18. Poliak, E.I.; Jonas, J.J. Initiation of dynamic recrystallization in constant strain rate hot deformation. ISIJ Int. 2003, 43, 684-691. [CrossRef]

19. Rollett, A. Recrystallization and Related Annealing Phenomena; Elsevier: Amsterdam, The Netherlands, 1995 ; pp. $248-259$.

20. Sellars, C. Modelling microstructural development during hot rolling. Mater. Sci. Technol. 1990, 6, 1072-1081. [CrossRef]

21. Mecking, H.; Kocks, U. A mechanism for static and dynamic recovery. In Strength of Metals and Alloys; Elsevier: Amsterdam, The Netherlands, 1979; pp. 345-350.

22. Ponge, D.; Gottstein, G. Necklace formation during dynamic recrystallization: Mechanisms and impact on flow behavior. Acta Mater. 1998, 46, 69-80. [CrossRef]

23. Wang, Z.; Ma, W.; Wang, C. Effect of Strain Rate on Hot Ductility of a Duplex Stainless Steel. Adv. Mater. Sci. Eng. 2019, 2019, 1-6. [CrossRef]

24. Wang, Z.; Xue, H.; Zhao, D. Microstructure Evolution and Surface Cracking Behavior of Superheavy Forgings during Hot Forging. Adv. Mater. Sci. Eng. 2018, 2018, 1-9. [CrossRef]

25. Prasad, Y.; Rao, K.; Sasidhar, S. Hot Working Guide: A Compendium of Processing Maps; ASM International: Almere, The Netherlands, 2015; pp. 3-9.

26. Aryshenskii, E.; HIRSCH, J.; Bazhin, V.; Kawalla, R.; Ulrich, P. Impact of Zener-Hollomon parameter on substructure and texture evolution during thermomechanical treatment of iron-containing wrought aluminium alloys. Trans. Nonferrous Met. Soc. China 2019, 29, 893-906. [CrossRef]

27. Ghazani, M.S.; Eghbali, B. A ductile damage criterion for aisi 321 austenitic stainless steel at different temperatures and strain rates. Arab. J. Sci. Eng. 2018, 43, 4855-4861. [CrossRef]

28. Jafari, M.; Najafizadeh, A. Correlation between Zener-Hollomon parameter and necklace DRX during hot deformation of 316 stainless steel. Mater. Sci. Eng. A 2009, 501, 16-25. [CrossRef]

29. Huiqin, C.; Wenwu, H.; Xiaodong, Z.; Fengming, Q.; Zhenxing, W. Hot deformation behavior and dynamic recrystallization of Mn18Cr18N steel with as-cast versus wrought starting structures. Procedia Eng. 2017, 207, 1779-1784. [CrossRef]

30. Qin, F.; Zhu, H.; Wang, Z.; Zhao, X.; He, W.; Chen, H. Dislocation and twinning mechanisms for dynamic recrystallization of as-cast Mn18Cr18N steel. Mater. Sci. Eng. A 2017, 684, 634-644. [CrossRef]

31. Zhao, H.; Qi, J.; Liu, G.; Su, R.; Sun, Z. A comparative study on hot deformation behaviours of low-carbon and medium-carbon vanadium microalloyed steels. J. Mater. Res. Technol. 2020, 9, 11319-11331. [CrossRef] 